\title{
ON A NEW GENERALIZATION OF OSTROWSKI TYPE INEQUALITY
}

\section{पाIIII}

\author{
B. G. PACHPATTE
}

\begin{abstract}
The aim of the present note is to establish a new generalization of Ostrowski type inequality involving two functions whose derivatives belong to $L_{p}$ spaces.
\end{abstract}

\section{Introduction}

The celebrated Ostrowski's inequality [4, p.468], which is a useful tool in numerical analysis, gives an estimate for the deviation of the values of a function from its mean value. In 1998, Dragomir and Wang [2] proved the following Ostrowski type inequality:

$$
\left|f(x)-\frac{1}{b-a} \int_{a}^{b} f(t) d t\right| \leq \frac{1}{(q+1)^{\frac{1}{q}}}\left[\left(\frac{x-a}{b-a}\right)^{q+1}+\left(\frac{b-x}{b-a}\right)^{q+1}\right]^{\frac{1}{q}}(b-a)^{\frac{1}{q}}\left\|f^{\prime}\right\|_{p},
$$

for all $x \in[a, b]$, where $f:[a, b] \rightarrow R$ is absolutely continuous function whose first derivative $f^{\prime} \in L_{p}[a, b], p>1, \frac{1}{p}+\frac{1}{q}=1$ and $\left\|f^{\prime}\right\|_{p}=\left(\int_{a}^{b}\left|f^{\prime}(t)\right|^{p} d t\right)^{\frac{1}{p}}$. During the past few years, a good deal of research activity has been constrated on the investigation of the inequalities of the type (1.1). The monographs [3,4] (see also [5,6]) contain a considerable amount of results related to such inequalities. The main object of this note is to establish a new generalization of the inequality (1.1) involving two functions whose derivatives belong to $L_{p}$ spaces. A new inequality of type (1.1) is also pointed out.

\section{Statement of results}

In what follows $R$ and ' denote respectively the set of real numbers and the derivative of a function. Let $[a, b] \subset R a<b$; and as usual for any function $h \in L_{p}[a, b], p>1$ we define $\|h\|_{p}=\left(\int_{a}^{b}|h(t)|^{p} d t\right)^{\frac{1}{p}}$.

Our main results are given in the following theorems.

Received December 16, 2005.

2000 Mathematics Subject Classification. 26D15, 26D20.

Key words and phrases. Ostrowski type inequality, absolutely continuous function, identities, Hölder's integral inequality, special means. 
Theorem 1. Let $f, g:[a, b] \rightarrow R$ be absolutely continuous functions whose derivatives $f^{\prime}, g^{\prime} \in L_{p}[a, b], p>1$. Then

$$
\begin{aligned}
& \left|f(x) g(x)-\frac{1}{2(b-a)}\left[g(x) \int_{a}^{b} f(t) d t+f(x) \int_{a}^{b} g(t) d t\right]\right| \\
& \leq \frac{1}{2(b-a)}\left[|g(x)|\left\|f^{\prime}\right\|_{p}+|f(x)|\left\|g^{\prime}\right\|_{p}\right](B(x))^{\frac{1}{q}}
\end{aligned}
$$

for all $x \in[a, b]$, where

$$
B(x)=\frac{1}{q+1}\left[(x-a)^{q+1}+(b-x)^{q+1}\right],
$$

for $x \in[a, b]$ and $\frac{1}{p}+\frac{1}{q}=1$.

Remark 1. By taking $g(x)=1$ and hence $g^{\prime}(x)=0$ in Theorem 1 and by simple calculation, we recapture the inequality (1.1) established by Dragomir and Wang in [2]. A slight variant of the inequality (2.1) is given in the following theorem.

Theorem 2. Let the hypotheses of Theorem 1 hold. Then

$$
\begin{aligned}
& \mid f(x) g(x)-\frac{1}{b-a}\left[g(x) \int_{a}^{b} f(t) d t+f(x) \int_{a}^{b} g(t) d t\right] \\
& \quad+\left(\frac{1}{b-a} \int_{a}^{b} f(t) d t\right)\left(\frac{1}{b-a} \int_{a}^{b} g(t) d t\right) \mid \\
& \leq \frac{1}{(b-a)^{2}}\left\|f^{\prime}\right\|_{p}\left\|g^{\prime}\right\|_{p}(B(x))^{\frac{2}{q}}
\end{aligned}
$$

for all $x \in[a, b]$, where $B(x)$ is given by $(2.2)$.

Remark 2. If we choose in (2.1) and (2.3), $x=\frac{a+b}{2}$, then we get the corresponding midpoint inequalities:

$$
\begin{aligned}
& \left|f\left(\frac{a+b}{2}\right) g\left(\frac{a+b}{2}\right)-\frac{1}{2(b-a)}\left[g\left(\frac{a+b}{2}\right) \int_{a}^{b} f(t) d t+f\left(\frac{a+b}{2}\right) \int_{a}^{b} g(t) d t\right]\right| \\
& \leq \frac{1}{2(b-a)}\left[g\left(\frac{a+b}{2}\right)\left\|f^{\prime}\right\|_{p}+f\left(\frac{a+b}{2}\right)\left\|g^{\prime}\right\|_{p}\right]\left(B\left(\frac{a+b}{2}\right)\right)^{\frac{1}{q}}, \\
& \mid f\left(\frac{a+b}{2}\right) g\left(\frac{a+b}{2}\right)-\frac{1}{b-a}\left[g\left(\frac{a+b}{2}\right) \int_{a}^{b} f(t) d t+f\left(\frac{a+b}{2}\right) \int_{a}^{b} g(t) d t\right] \\
& \quad+\left(\frac{1}{b-a} \int_{a}^{b} f(t) d t\right)\left(\frac{1}{b-a} \int_{a}^{b} g(t) d t\right) \mid \\
& \leq \frac{1}{(b-a)^{2}}\left\|f^{\prime}\right\|_{p}\left\|g^{\prime}\right\|_{p}\left(B\left(\frac{a+b}{2}\right)\right)^{\frac{2}{q}} .
\end{aligned}
$$




\section{Proofs of Theorems 1 and 2}

From the hypotheses, we have the following identities (see $[2,3,4])$ :

$$
\begin{aligned}
& f(x)-\frac{1}{b-a} \int_{a}^{b} f(t) d t=\frac{1}{b-a} \int_{a}^{b} k(x, t) f^{\prime}(t) d t, \\
& g(x)-\frac{1}{b-a} \int_{a}^{b} g(t) d t=\frac{1}{b-a} \int_{a}^{b} k(x, t) g^{\prime}(t) d t,
\end{aligned}
$$

for $x \in[a, b]$, where

$$
k(x, t)=\left\{\begin{array}{l}
t-a \text { if } t \in[a, x], \\
t-b \text { if } t \in(x, b] .
\end{array}\right.
$$

Multiplying both sides of (3.1) and (3.2) by $g(x)$ and $f(x)$ respectively, adding the resulting identities and rewriting we have

$$
\begin{aligned}
& f(x) g(x)-\frac{1}{2(b-a)}\left[g(x) \int_{a}^{b} f(t) d t+f(x) \int_{a}^{b} g(t) d t\right] \\
& =\frac{1}{2(b-a)}\left[g(x) \int_{a}^{b} k(x, t) f^{\prime}(t) d t+f(x) \int_{a}^{b} k(x, t) g^{\prime}(t) d t\right] .
\end{aligned}
$$

From (3.3), using the properties of modulus and Hölder's integral inequality, we have

$$
\begin{aligned}
\left|f(x) g(x)-\frac{1}{2(b-a)}\left[g(x) \int_{a}^{b} f(t) d t+f(x) \int_{a}^{b} g(t) d t\right]\right| \\
\leq \frac{1}{2(b-a)}\left[|g(x)| \int_{a}^{b}|k(x, t)|\left|f^{\prime}(t)\right| d t+|f(x)| \int_{a}^{b}|k(x, t)|\left|g^{\prime}(t)\right| d t\right] \\
\leq \frac{1}{2(b-a)}\left[|g(x)|\left(\int_{a}^{b}|k(x, t)|^{q} d t\right)^{\frac{1}{q}}\left(\int_{a}^{b}\left|f^{\prime}(t)\right|^{p} d t\right)^{\frac{1}{p}}\right. \\
\left.+|f(x)|\left(\int_{a}^{b}|k(x, t)|^{q} d t\right)^{\frac{1}{q}}\left(\int_{a}^{b}\left|g^{\prime}(t)\right|^{p} d t\right)^{\frac{1}{p}}\right] \\
=\frac{1}{2(b-a)}\left[|g(x)|\left\|f^{\prime}\right\|_{p}+|f(x)|\left\|g^{\prime}\right\|_{p}\right]\left(\int_{a}^{b}|k(x, t)|^{q} d t\right)^{\frac{1}{q}} .
\end{aligned}
$$

By simple calculation we have

$$
\begin{aligned}
\int_{a}^{b}|k(x, t)|^{q} d t & =\int_{a}^{x}|t-a|^{q} d t+\int_{x}^{b}|t-b|^{q} d t \\
& =\int_{a}^{x}(t-a)^{q} d t+\int_{x}^{b}(b-t)^{q} d t \\
& =\frac{1}{q+1}\left[(x-a)^{q+1}+(b-x)^{q+1}\right]=B(x)
\end{aligned}
$$


Using (3.5) in (3.4) we get (2.1). Multiplying the left sides and right sides of (3.1) and (3.2) we have

$$
\begin{aligned}
f(x) & g(x)-\frac{1}{b-a}\left[g(x) \int_{a}^{b} f(t) d t+f(x) \int_{a}^{b} g(t) d t\right] \\
& +\left(\frac{1}{b-a} \int_{a}^{b} f(t) d t\right)\left(\frac{1}{b-a} \int_{a}^{b} g(t) d t\right) \\
= & \frac{1}{(b-a)^{2}}\left(\int_{a}^{b} k(x, t) f^{\prime}(t) d t\right)\left(\int_{a}^{b} k(x, t) g^{\prime}(t) d t\right) .
\end{aligned}
$$

From (3.6), using the properties of modulus, Hölder's integral inequality and (3.5), we have

$$
\begin{aligned}
\mid f(x) & g(x)-\frac{1}{b-a}\left[g(x) \int_{a}^{b} f(t) d t+f(x) \int_{a}^{b} g(t) d t\right] \\
& +\left(\frac{1}{b-a} \int_{a}^{b} f(t) d t\right)\left(\frac{1}{b-a} \int_{a}^{b} g(t) d t\right) \mid \\
\leq & \frac{1}{(b-a)^{2}}\left(\int_{a}^{b}|k(x, t)|\left|f^{\prime}(t)\right| d t\right)\left(\int_{a}^{b}|k(x, t)|\left|g^{\prime}(t)\right| d t\right) \\
\leq & \frac{1}{(b-a)^{2}}\left(\int_{a}^{b}|k(x, t)|^{q} d t\right)^{\frac{1}{q}}\left(\int_{a}^{b}\left|f^{\prime}(t)\right|^{p} d t\right)^{\frac{1}{p}} \\
& \times\left(\int_{a}^{b}|k(x, t)|^{q} d t\right)^{\frac{1}{q}}\left(\int_{a}^{b}\left|g^{\prime}(t)\right|^{p} d t\right)^{\frac{1}{p}} \\
= & \frac{1}{(b-a)^{2}}\left\|f^{\prime}\right\|_{p}\left\|g^{\prime}\right\|_{p}\left(\int_{a}^{b}|k(x, t)|^{q} d t\right)^{\frac{2}{q}} \\
= & \frac{1}{(b-a)^{2}}\left\|f^{\prime}\right\|_{p}\left\|g^{\prime}\right\|_{p}(B(x))^{\frac{2}{q}} .
\end{aligned}
$$

This completes the proof of inequality (2.3).

\section{Application to some special means}

In this section, we discuss the application of the inequality (2.5) to lower and upper bounds estimation of some relationships between the following means:

(a) The arithmetic mean: $A=A(a, b)=\frac{a+b}{2}, a, b \geq 0$. (b) The geometric mean: $G=$ $G(a, b)=\sqrt{a b}, a, b \geq 0 .(c)$ The logarithmic mean: $L=L(a, b)= \begin{cases}\frac{b-a}{\ln b-\ln a}, & \text { if } a \neq b \\ a, & \text { if } a=b .\end{cases}$ 
Let $a, b>0, f \in L_{2}[a, b]$ and consider the function $f:[a, b] \subset(0, \infty) \rightarrow R$ defined by $f(x)=\frac{1}{x}$ and $g=f$. Then by simple computation

$$
\begin{gathered}
f\left(\frac{a+b}{2}\right)=g\left(\frac{a+b}{2}\right)=\frac{1}{A}, \\
\frac{1}{b-a} \int_{a}^{b} f(t) d t=\frac{1}{b-a} \int_{a}^{b} g(t) d t=\frac{1}{L}, \\
\left\|f^{\prime}\right\|_{2}^{2}=\left\|g^{\prime}\right\|_{2}^{2}=\frac{(b-a)\left(a^{2}+b^{2}+G^{2}\right)}{3 G^{6}}, \\
B\left(\frac{a+b}{2}\right)=\frac{1}{12}(b-a)^{3} .
\end{gathered}
$$

Using the above facts in (2.5), it is easy to see that the following inequality holds:

$$
\left|\frac{1}{A}\left(\frac{1}{A}-\frac{2}{L}\right)+\frac{1}{L^{2}}\right| \leq \frac{(b-a)^{2}\left(a^{2}+b^{2}+G^{2}\right)}{36 G^{6}} .
$$

Remark 3. As discussed above (see also [1]), one can also derive bounds for differences and ratios of the above means and other means noted in [1], when the function $f$ is defined by $f(x)=x^{p}, p \in R \backslash\{-1,0\}$ and $f(x)=\log x$. Here, we do not discuss the details.

\section{References}

[1] N. S. Barnett, S. S. Dragomir and A. Sofo, Better bounds for an inequality of Ostrowski type with applications, RGMIA Res. Rep. Coll. 3(2000), 113-122.

[2] S. S. Dragomir and S. Wang, A new inequality of Ostrowski type in $L_{p}$ norm, Indian Jour. Math. 40(1998), 299-304.

[3] S. S. Dragomir and Th. M. Rassias (Eds.), Ostrowski Type Inequalities and Applications in Numerical Integration, Kluwer Academic Publishers, Dordrecht, 2002.

[4] D. S. Mitrinović, J. E. Pečarić and A. M. Fink, Inequalities Involving Functions and Their Integrals and Derivatives, Kluwer Academic Publishers, Dordrecht, 1994.

[5] B. G. Pachpatte, A note on Ostrowski like inequalities, J. Inequal. Pure and Appl. Math. 6Art.114, 2005.

[6] B. G. Pachpatte, On Ostrowski-Grüss-Čebyšev type inequalities for functions whose modulus of derivatives are convex, J. Inequal. Pure and Appl. Math. 6Art.128, 2005.

57 Shri Niketan Colony, Near Abhinay Talkies, Aurangabad 431001 (Maharashtra) India.

E-mail: bgpachpatte@gmail.com 